\title{
“Someone's Got My Back": Older People's Experience of the Coaching for Healthy Ageing Program for Promoting Physical Activity and Preventing Falls
}

\author{
Abby Haynes, Catherine Sherrington, Geraldine Wallbank, David Lester, Allison Tong, \\ Dafna Merom, Chris Rissel, and Anne Tiedemann
}

\begin{abstract}
The Coaching for Healthy Ageing trial evaluated the impact on physical activity (PA) and falls based on a year-long intervention in which participants aged $60+$ receive a home visit, regular health coaching by physiotherapists, and a free activity monitor. This interview study describes the participants' experiences of the intervention and ideas for improvement. The authors sampled purposively for maximum variation in experiences. The data were analyzed thematically by two researchers. Most of the 32 participants reported that the intervention increased PA levels, embedded activities, and generated positivity about PA. They were motivated by quantified PA feedback, self-directed goals, and person-centered coaching. Social connectivity motivated some, but the intervention did not support this well. The intervention structure allowed participants to trial and embed activities. Autonomy and relatedness were emphasized and should be included in future program theory. The authors identified synergistic effects, likely "essential ingredients," and potential areas for improving this and similar interventions.
\end{abstract}

Keywords: activity tracking, health coaching, intervention trial, older adults, qualitative methods

Physical activity (PA) is essential for optimized health in older age (Bauman, Merom, Bull, Buchner, \& Fiatarone Singh, 2016). Even when taken up later in life, PA has significant health benefits, reducing the risk of functional limitations, disability, major noncommunicable diseases, and overall mortality (Age UK, 2011; Bauman et al., 2016; Daskalopoulou et al., 2017; Hamer, Lavoie, \& Bacon, 2014; Koster, Stenholm, \& Schrack, 2018; World Health Organization, 2015). It is also associated with better sleep, mental health, and cognitive function (Batchelor et al., 2016; Hill \& Heesch, 2018; Koster et al., 2018; Stathi, Fox, \& McKenna, 2002). Healthier aging has widespread social and economic benefits, contributing to lower health costs and higher rates of participation in the workforce, volunteering, and caring for family members (Age UK, 2011; Batchelor et al., 2016; Cadilhac et al., 2011). However, there is considerable evidence globally that too few older adults are

(C) 2021 The Authors. Published by Human Kinetics, Inc. This is an Open Access article distributed under the terms of the Creative Commons Attribution-NonCommercial-NoDerivatives 4.0 International License, CC BY-NC-ND 4.0, which permits the copy and redistribution in any medium or format, provided it is not used for commercial purposes, no modifications are made, appropriate credit is given, and a link to the license is provided. See http://creativecommons.org/licenses/by-nc-nd/4.0. This license does not cover any third-party material that may appear with permission in the article. For commercial use, permission should be requested from Human Kinetics, Inc., through the Copyright Clearance Center ( http://www.copyright.com).

Haynes, Sherrington, Wallbank, Lester, and Tiedemann are with the Institute for Musculoskeletal Health, The University of Sydney, Sydney, NSW, Australia; and the Sydney Local Health District, Sydney, NSW, Australia. Haynes, Sherrington, Wallbank, Lester, Tong, and Tiedemann are with the School of Public Health, Faculty of Medicine and Health, The University of Sydney, Sydney, NSW, Australia. Tong is with the Centre for Kidney Research, The Children's Hospital at Westmead, Westmead, NSW, Australia. Merom is with Western Sydney University, School of Health Science, Penrith, NSW, Australia. Rissel is with the NSW Office of Preventive Health, Liverpool Hospital, Liverpool, NSW, Australia. Haynes (abby.haynes@sydney.edu.au) is corresponding author. sufficiently physically active to maximize the health benefits (Hill $\&$ Heesch, 2018). Older rural populations with lower socioeconomic status and education, ethnic minorities, and older people with disabilities are more likely to be inactive (Age UK, 2011; Kosma \& Cardinal, 2016; Mendoza-Vasconez et al., 2016).

Poor motivation is a primary reason for inactivity among older adults (Kosma \& Cardinal, 2016). Motivation may be affected by low self-efficacy, chronic medical conditions, pain, and fear about injury (Hill, 2018). In particular, fear of falling can lead to the avoidance of PA (Hornyak et al., 2013; Stathi, Fox, Withall, Bentley, \& Thompson, 2014). Social and environmental contexts can profoundly impact the options for PA (World Health Organization, 2015). Important factors include financial costs, time constraints (Hoare, Stavreski, Jennings, \& Kingwell, 2017), and poor adaptation of programs for older adults (Hill, 2018), including those with cultural or gender-specific preferences about exercise (Devereux-Fitzgerald, Powell, Dewhurst, \& French, 2016; Franco, Tong, et al., 2015; Kosma \& Cardinal, 2016). Older adults may prefer flexible, noncompetitive activities with people of a similar age (Burton, Khan, \& Brown, 2012). Fun, a sense of purpose, social interaction, minimizing the impacts of aging, improved energy, and other potential health gains can motivate older adults to be active, but the uses and impacts of these factors in PA interventions are not well understood (Allender, Cowburn, \& Foster, 2006; Devereux-Fitzgerald et al., 2016; Franco, Tong, et al., 2015; Rhodes \& Pfaeffli, 2010; Stathi, McKenna, \& Fox, 2010).

Health coaching is a theory-informed evidence-based strategy that can significantly increase PA in people aged 60 years and over (Oliveira et al., 2017) and help to sustain long-term health intervention effectiveness (Dejonghe, Becker, Froboese, \& Schaller, 2017). Structured telephone coaching can lead to positive changes in health behaviors, including PA (Eakin, Lawler, Vandelanotte, \& Owen, 2007), and provides home-based access to exercise programs, which may be preferred by older people with a history of falls and/or mobility difficulties (Franco, Howard, et al., 2015). However, the current 
evidence on the effectiveness of health coaching provided specifically by physiotherapists is nascent and mixed (Rethorn \& Pettitt, 2019).

Activity trackers increase PA in adults of all ages, including older adults (Mercer, Li, Giangregorio, Burns, \& Grindrod, 2016; Oliveira, Sherrington, Zheng, et al., 2019) and inactive populations (Kang, Marshall, Barreira, \& Lee, 2009; Mercer et al., 2016), having greater effects than educational, behavioral, or social intervention strategies alone (Heath et al., 2012). Activity trackers, both simple and Internet-connected, provide objective reliable data about total daily steps (Paul et al., 2015) and are acceptable to older people (Tiedemann, Hassett, \& Sherrington, 2015).

There is mixed evidence on the effectiveness of interventions that combine health coaching and activity tracking to promote PA in older people. Some studies have found no effect on PA (e.g., Oliveira, Sherrington, Paul, et al., 2019; Thompson, Kuhle, Koepp, McCrady-Spitzer, \& Levine, 2014), while others have shown increased and sustained activity (e.g., Brickwood, Williams, Watson, \& O'Brien, 2020; Tiedemann et al., 2015). One study found that pedometers did not increase PA when used as an adjunct to health coaching, but may have motivated participants to remain in the trial (McMurdo et al., 2010). It is unclear how contextual factors, coaching quality, or other variables may have shaped these findings. Consequently, the most effective intervention design remains elusive (Thompson et al., 2014), as does the information required to adapt programs for best effect with different groups and in different contexts. A better understanding of the experiences and views of older adults participating in PA and fallprevention trials may provide some of the essential information required to improve intervention uptake and effectiveness (Devereux-Fitzgerald et al., 2016; Taylor \& Pescatello, 2016).

\section{The Intervention: Coaching for Healthy Ageing}

The Coaching for Healthy Ageing (CHAnGE) trial is a clusterrandomized controlled study that aims to test the effectiveness and cost-effectiveness of a healthy aging program targeting falls and physical inactivity among older people. The participants were community-dwelling people aged 60+ years from three locations in Australia: Sydney (a large metropolitan center), Orange, and the Blue Mountains (regional towns). The study protocol is published elsewhere (Tiedemann et al., 2016).

The participating groups were recruited from established community groups via information sessions provided by researchers/coaches and were randomized to either (a) a healthy eating intervention (control) or (b) a 12-month PA and fall-prevention intervention involving a home visit, a pedometer-based activity tracker, and telephone health coaching provided by a physiotherapist every 2 weeks. The primary outcomes were objectively measured PA at 12 months postrandomization and self-reported falls during the 12-month follow-up.

This study describes the experiences of the participants in the PA and fall-prevention arm and seeks to identify how this or other similar interventions might be refined to increase acceptability and effectiveness.

\section{Methods}

\section{Theoretical Basis}

This interview study was informed by a hybrid program theory. Firstly, it incorporated the COM-B model (Michie, van Stralen, \&
West, 2011), which underpinned the design of the CHAnGE intervention. This model identifies three conditions that determine an individual's behavior: intrinsic physical and psychological capabilities (C); extrinsic social and environmental opportunities $(\mathrm{O})$; and motivators $(\mathrm{M})$, which may be reflective (thinking with the head) or automatic (emotional "thinking" with the heart). Capability, opportunity, and motivation interact to generate behavior (B) that, in turn, feeds back to influence the three behavior conditions.

Given that CHAnGE emphasized sustained motivation and choice, this study also drew on self-determination theory (Ryan \& Deci, 2017), an empirical theory that has informed the design and evaluation of multiple interventions aimed at increasing PA (Teixeira, Carraça, Markland, Silva, \& Ryan, 2012). Self-determination theory identifies three enduring psychological needs for optimal motivation: competence (belief in one's ability to attain desired outcomes), autonomy (the ability to use volition), and relatedness (feeling close to, trusting of, and cared for by others) (Ryan \& Deci, 2017). Competence is well-represented in the COMB model, but autonomy and relatedness are not.

Finally, we incorporated the concept of competing demands from a systematic review of 132 studies that examined older people's views on participation in PA (Franco, Tong, et al., 2015). This was conceptualized as an amalgam of all the elements (intrinsic and extrinsic) in the COM-B model.

Figure 1 illustrates our conceptualization of this hybrid theory. This is a schematic framework that does not reflect the full range of hypothesized relationships (for e.g., autonomy and relatedness probably both require some degree of capability and opportunity), but it enabled us to identify distinct theoretical concepts for use in the interview guide and in data coding.

\section{Recruitment}

All CHAnGE trial participants were asked to complete an evaluation form at the 6-month follow-up, which included a question about whether they would be willing to participate in a semistructured interview. Those who said "Yes" $(n=127)$ were considered the sample frame for this study.

Sampling was purposive. The health coaches aimed for maximum variation in the participants' (a) engagement with the intervention, as perceived by their coach; (b) socioeconomic status, using

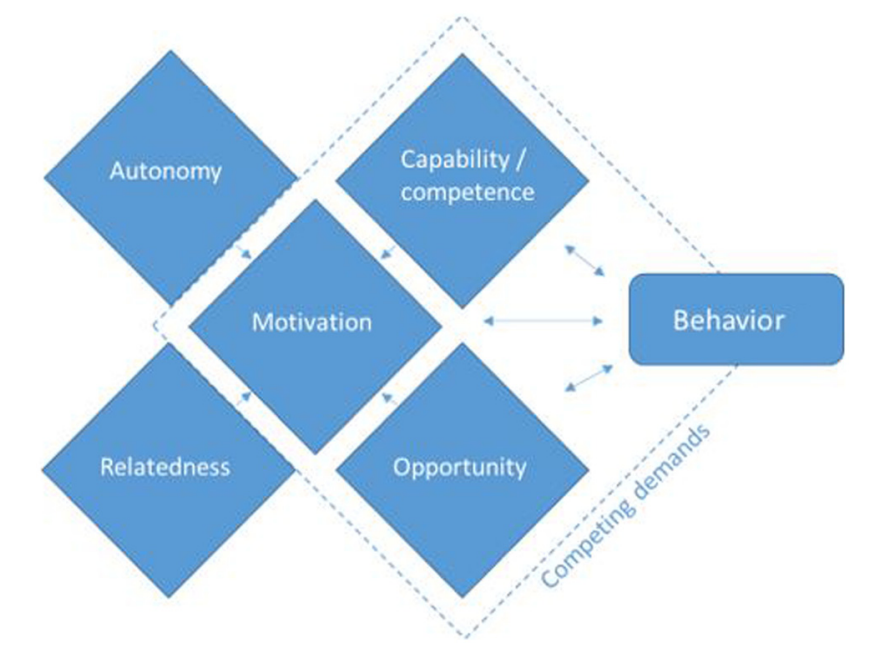

Figure 1 - Adapted from The COM-B system in Michie et al. (2011). Ryan and Deci (2017); and Franco et al. (2015). 
postcodes as a proxy; and (c) geographic location. We sought to include proportions of men and women that reflected the numbers in the intervention: $70 \%$ female and $30 \%$ male. The coaches reconfirmed their willingness to participate with each individual and, with permission, gave their contact details to the interviewers. Thirty-three people were invited to participate, and one declined due to health problems. Recruitment ceased when we met our maximum variation sampling requirements, and the ongoing analysis indicated that both the depth and informational quality of the data were sufficient to answer our research questions and that current interviews were not yielding significantly new conceptual information (Fusch \& Ness, 2015; Malterud, Siersma, \& Guassora, 2015).

\section{Data Collection}

The interview questions (Supplementary Material 1 [available online]) focused on reasons for participation in the CHAnGE trial; views about PA and falls; barriers and enablers to participation; experiences of health coaching, activity monitoring, and social connection; any perceived impacts of participation; factors affecting the likelihood of maintenance; and suggestions for improvements in CHAnGE. The interviews were semistructured, and the participants could raise other topics of relevance. Prompts were used to elicit information relating to each of the theoretical constructs described above and to explore the participants' beliefs about how the intervention worked (i.e., their perceptions of causal mechanisms) (Manzano, 2016).

The interviews were conducted over the telephone by experienced qualitative researchers (A. Haynes and D. Lester) and audio recorded. The interviewers had no prior relationships with the participants or the health coaches. To reduce social desirability bias, the participants were informed that the interviewers were not involved in the intervention design or delivery and that the health coaches would not have access to identifiable data. Audio recordings were professionally transcribed verbatim and checked for errors by the interviewers.

\section{Data Analysis}

The transcripts were analyzed in NVivo 12 (QSR International, Melbourne, Australia) using an interpretive description approach. This approach incorporates common qualitative analytical techniques, including emersion in the data, a "constant comparison" of data to identify thematic patterns and relationships across cases, and theorizing about explanatory factors (Thorne, 2000, 2008).

As the interviews progressed, a draft coding frame was developed to capture themes and to categorize data relating to theoretical constructs and intervention components. The coding frame was trialed by A. Haynes and G. Wallbank, who independently coded a proportion of the transcripts and then codeveloped and tested a revised version, which was applied to all transcripts. The draft themes and findings were discussed with coauthors C. Sherrington and A. Tong to explore a wider range of possible thematic interpretations. Disagreements were resolved through discussion. Codes continued to evolve throughout the analysis, with continued dialogue between the coders to increase concordance (Patton, 1999; White, Oelke, \& Friesen, 2012).

In a second round of more inductive thematic analysis, we examined each of the categories of coded data to develop explanations that captured the variation and prevalence of information, which helped to answer, or provided additional insights into, our research questions (Braun \& Clarke, 2006; Thorne, 2008). See Supplementary Material 2 (available online) for the final coding frame.

Research rigor was strengthened via independent coding; researcher triangulation; and a critical review of the developing themes, including searching for disconfirming data, as part of the constant comparative process (Elliott \& Timulak, 2005; Johnson \& Waterfield, 2004; Thorne, 2008; Tong, Sainsbury, \& Craig, 2007).

\section{Ethical Approvals}

Ethical approval for this study was included in the CHAnGE trial approvals provided by The University of Sydney Human Research Ethics Committee, reference no. 2015/517. All participants gave prospective written informed consent at the trial commencement and verbal consent at the start of their interview. All were free to withdraw from the study at any time.

\section{Results}

\section{Participants}

Thirty-two people participated in semistructured interviews: 22 $(69 \%)$ women and $10(31 \%)$ men. They were aged from 60 to 82 years at the start of the intervention (mean 72, SD 6.2). Seventeen lived in metropolitan Sydney, 16 in regional towns, 23 in high socioeconomic areas, and nine in low socioeconomic areas. Seven were employed or had a formal volunteer role, while 17 had caring responsibilities. Two spoke English as a second language. At the baseline, their average daily steps ranged from 2,900 to 13,872 (mean 5,991), with only three achieving over 10,000 steps daily. Seven participants had fallen prior to the intervention, two of whom reported two falls. All were at least 6 months through the intervention when the interviews took place. The interviews ranged in duration from 23 to $61 \mathrm{~min}$, with an average duration of $37 \mathrm{~min}$.

Illustrative quotes are used throughout this section. The participants' sex and age at trial commencement are shown, but the quotes are otherwise deidentified to protect anonymity, including the removal of the locations and coaches' names. The number of responses are shown for the topics that all participants were asked about. This indicates the prevalence and diversity of perspectives within our sample, but is not generalizable to the whole trial cohort or to wider populations.

\section{Experiences of the Intervention}

Activity monitoring. The majority of participants $(n=29)$ found it highly motivating to receive direct PA feedback via their activity tracker, largely because it enabled them to quantify their progress: "I need some set standards and the Fitbit was that. It was concrete. It was what you really did" (female, 76). Twenty-two participants said the combination of activity tracking and personal goals made them push themselves harder:

The Fitbit is a motivator. Every time ... I just have a look and I think "Oh, that's not very good today" I make a point of doing extra walking. ... [Or], if I have been doing well, I think "That's good, I might try and get to 10,000 today instead of 8,000 ". ... So yeah, it's pushing me along. (female, 71)

The activity data also encouraged some of the less active participants to engage with exercise in the early stages of the program:

[The activity tracker] made me do it, you know. Now I don't want to miss going for my walks, but in the beginning it really 
gave me the incentive to get going because you saw at the end of the day how many steps you had done. (female, 73)

The credibility of the activity tracker in providing reliable data was emphasized by several participants: "I was a bit of a sceptic about health technology . . . . Now I'm a convert. ... The Fitbit doesn't lie... the accuracy of the feedback is good. ... I see the value of it now" (male, 71).

The data also prevented self-deception- "it keeps you honest" (male, 77) — and facilitated "self-competition" (trying to best previous scores) and playful comparison with family, friends, and other participants in CHAnGE:

People say, "How many have you done today?" and I bring it out and have a look at it, and I can tell them immediately. They're very impressed. And also my daughters have got one and we have a little competition to see how far we can go each week, and I've won a couple of times. (female, 73)

The activity tracker technology inspired mixed feelings. Some participants liked their basic easy-to-master model, while others complained that it was too basic, it ate batteries, broke, or was easy to lose. Several hoped to upgrade to models that could be worn in water or would prompt them to move and track their sleep and weight. A few participants expressed enthusiasm for their own more sophisticated devices, using them to monitor swimming and aqua aerobics, earn "badges" for achieving milestones, and maximize their ratings in specific areas, such as climbing stairs.

In most cases, the benefits of activity monitoring were enhanced by knowing the coaches were tracking the activity scores and would be telephoning to discuss them:

As soon as I get up in the morning I grab my Fitbit; it's just become an automatic. So that alone would be one thing, but then knowing that $\mathrm{X}$ is going to phone every fortnight is that added incentive to keep on it. Because the Fitbit is not a human being, obviously, and $\mathrm{X}$ is. ... [She] has a conversation about how things are going and sort of does that gentle encouragement to keep on going. (female, 63)

Health coaching. The perceptions of health coaching were extremely positive, even with the participants who stated they did not find the intervention helpful. This centered on the coaches' attributes and skills, supported by the structural characteristics of the intervention (Table 1). Together, they enabled trusting and, in most cases, productive relationships to develop.

Most participants $(n=28)$ felt coaching had helped them shape personal goals and increased their motivation. In common with other studies (e.g., Liddy, Johnston, Irving, Nash, \& Ward, 2015; Wolever et al., 2013), accountability was frequently identified as an explanation for why coaching prompted behavior change: "I think that's human nature, isn't it? If you know someone's looking over your shoulder and checking your results, you try harder" (male, 72). What was notable in this data, however, was the assertion that accountability functioned well because it was in the context of a supportive, mutually esteemed relationship:

I did not think at my age that I was going to respond well to somebody checking up on me, but I do ... because she [the coach] is always encouraging and because I like her and it's a nice phone call. (female, 71 )

The coaches' expert guidance was strongly valued. Eighteen participants talked about beneficial exercises and resources, emphasizing the exploratory and responsive dialogue that enabled well-tailored options to emerge. Many also mentioned the regularity of contact, the home visit, and the availability of coaches as positives: "That's what's great, when something goes awry you've got someone right on tap to tell you what to do" (female, 71).

\section{Recruitment as a member of an existing community group.}

The intervention was not very successful in generating PA-related social interaction (conversations or shared activities) among members of recruited groups. Nearly half $(n=15)$ the participants had little or no CHAnGE-related social contact with their recruitment group peers, yet one third of those who expressed a preference said they would like more interaction with their community group. The reasons for poor connection varied. Some did not know which group members were taking part in the trial, others had left the group where recruitment occurred, and a few small neighborhood groups struggled with high drop-out rates, sometimes due to illness or death.

\section{Table 1 Most Frequently Described Explanatory Factors for Why Coaching was Beneficial}

\begin{tabular}{|c|c|}
\hline Main explanatory factor & Description \\
\hline \multicolumn{2}{|l|}{ Coach characteristics } \\
\hline Encouragement & $\begin{array}{l}\text { Expressing belief in the participant and their capabilities, pushing gently, and suggesting possible solutions, but also } \\
\text { advocating other forms of self-care when appropriate, never making them feel bad about unachieved goals }\end{array}$ \\
\hline Person-centered respect & Supporting autonomy/self-direction, recognizing self-knowledge, active listening, and being nonjudgmental \\
\hline Professional expertise & $\begin{array}{l}\text { Credibility and skill in providing evidence-based guidance and resources, breadth of knowledge in wider spheres of } \\
\text { health and mental health, and cultural competence }\end{array}$ \\
\hline "Being human" & $\begin{array}{l}\text { Likeability, friendliness, empathy, sense of humor, showing an interest in the whole person, willingness to chat } \\
\text { informally, and share interests }\end{array}$ \\
\hline $\begin{array}{l}\text { Commitment and } \\
\text { reliability }\end{array}$ & $\begin{array}{l}\text { Doing what they say they will do, going the extra mile (e.g., attending aqua class, exchanging emails), and practicing } \\
\text { what they preach }\end{array}$ \\
\hline \multicolumn{2}{|l|}{ Structural characteristics } \\
\hline $\begin{array}{l}\text { Regularity and duration } \\
\text { of contact }\end{array}$ & Sufficient to put strategies into action, maintain accountability, and allow a relationship to develop \\
\hline In-person contact & Meeting face-to-face at the recruitment session and home visit \\
\hline Mode of contact & Talking on phone (rather than communicating via text or email) enabled dynamic conversation \\
\hline
\end{tabular}


Seven participants had a companion with whom they could walk or attend an exercise class, but others were happy "going it alone," and some avoided interaction because they preferred their own company or sought "privacy" or, in one case, due to annoyance with peers they felt were too competitive: "A couple of them are out there to go, 'Look at me. Look at me. I've done more steps than you.' And to me that's not what it's all about" (female, 65).

For others, however, recruitment from within their community group was an added incentive to take part in CHAnGE because of the promise of increased social interaction and, therefore, enjoyment of PA:

The fact that the people in the group were doing it as well made it more interesting for me, just because I'm a social person. I also really like the idea of having some support in keeping myself healthy rather than me trying to drive myself all the time. (female, 65)

But it also included a feeling of security, "If you're in a group it's easier. If you're all doing something together it makes you feel safer." (male, 76)

Where teams of friends joined CHAnGE together, PA often became part of their everyday social conversation and, in some cases, may have reinforced the reconceptualization of PA described in the next section:

The other day we went to the theatre and we parked the car a long way away. I would have said "Oh, damn!" in the past, but I said to my friend "Oh, we can do our steps." She said, "Yes," because she's on the program as well. I think it's an attitudinal change. (female, 64)

The participants who were motivated by PA with peers or family members prior to the intervention valued social connection in CHAnGE more highly. The quality of existing relationships, geographical proximity to other group members, and features of the recruitment context was mentioned as mediators. For example, it seemed that group coherence might be stronger where people were recruited from towns and retirement villages with smaller populations than from large urban centers. Five enjoyable and motivating aspects of group connection were described (Table 2).

Unfortunately, there were many examples where shared exercise was hampered by incompatibility in fitness or other capabilities, and therefore, in goals and preferred activities, including whether their main focus was general fitness or fall prevention: "My wife and I often walk separately. She had a higher goal and I can't keep up with her walking at her exercise speed" (male, 81).

\section{Impact and Maintenance of PA and Fall-Prevention Exercise}

Nineteen participants reported that participation in the CHAnGE trial had increased their level of regular exercise and/or their repertoire of activities:

It's enlarged or expanded my challenges of myself. ... And it does get me out and about more frequently. It gives me goals that I can achieve and goals that I can raise. It, I don't know, makes me feel good. (female, 76)

Several participants noted that activity was now embedded or "locked in" to their everyday life: "The routine is there now, it's set" (male, 77). And some foresaw this continuing in the long term:

I won't give it up ... the other day in my fitness class ... [the instructor] said "I've never seen so many fit older people," meaning me and a few of the others. I said, "Oh, well, I'm 71 and I hope to be doing this when I'm $80 \ldots$... I reckon I could still do all this at 80 “cause I've worked my way up.” (female, 70)

\section{Table 2 Aspects of Group Membership Contributing to Participants' Enjoyment and Motivation}

\begin{tabular}{|c|c|}
\hline 1. Companionship and fun during exercise & $\begin{array}{l}\text { - I think anything that's shared [makes a difference]. It's much more fun walking with } \\
\text { somebody than walking alone. (female, 82) } \\
\text { - I go [to the aquatic centre] because I enjoy it. It's my social for the day. (female, 80) }\end{array}$ \\
\hline $\begin{array}{l}\text { 2. A sense of community or team identity, including } \\
\text { wanting to be part of the local "conversation" }\end{array}$ & $\begin{array}{l}\text { - Your program is like a team thing. I love it 'cause I've got other people that are on the } \\
\text { same program. ... I find that being part of the team is terrific. ... I suppose it's a } \\
\text { "belonging" thing. (female. 76) } \\
\text { - I think we enjoy that sense we're not alone in doing this, you know what I mean? And } \\
\text { we can bounce off one another. (male, 71) }\end{array}$ \\
\hline 3. Mutual support and encouragement & $\begin{array}{l}\text { - Six of my friends are in your program. It's really good. ... [They'll say] "I've only } \\
\text { done 5,000 steps" and I'll say, "Well go and do the rest of them!" ... [They'll say] } \\
\text { "You've walked around France!"'... I send them [badges] to my friends and they send } \\
\text { me theirs. (female, 64) } \\
\text { - We just check on each other. ... I think we all give each other encouragement. That's a } \\
\text { big thing too, really, the encouragement you get from other people so that you're not } \\
\text { feeling isolated. (female, 76) }\end{array}$ \\
\hline 4. Competition and comparison & $\begin{array}{l}\text { - I discuss with the girls about their steps and they get a shock when they know I've done } \\
10,000 \text { every day. ... they think that they better lift their game a bit. (female, 76) } \\
\text { - Participating cheered me up because there's a few people where I live that were doing it } \\
\text { as well, so we were sort of comparing and trying to out-do each other. (female, 80) }\end{array}$ \\
\hline 5. Having a shared interest & $\begin{array}{l}\text { - It's helped us socially with each other ... sometimes two or three of us will be out and } \\
\text { we'll bump into another group that's out and then we'll all go for coffee, so it's been } \\
\text { great. (female, 71) } \\
\text { - I already had them as friends so, if anything, it added that extra topic of conversation. } \\
\text { (female, 61) }\end{array}$ \\
\hline
\end{tabular}


A few participants had chosen not to work toward specific goals, but felt the program provided a general impetus to be active:

Well it sort of pushes me to get out and do something rather than sit in front of the TV or computer. ... I'll realise that I haven't done my steps today or I haven't [used my weights], you know? I better get out and do a bit of exercise. (male, 77)

Some developed a more positive attitude in that they now regarded PA as a health solution, placing exercise and avoidance of long sedentary periods higher on their agenda:

I've probably got a little more enthusiasm for walking ... I'm aware that I feel good when I've had the walks ... I enjoyed it before but I think doing it as an exercise like this for 12 months that I've become more conscious of how good it is for my health. (female, 80)

For several participants, this was a reconceptualization of PA as something to embrace rather than avoid:

In the past, basically most of my adult life, if I was walking from the house up to my studio, I'd be thinking, "I have to take everything up there in one go" ... and if I forgot something I would get very angry at myself and think, "Oh, I've gotta go all the way back." But since I've had the Fitbit I think, "Okay, that's more steps, that's good ... it's making me healthier." (female, 65)

Their reconceptualization of PA had also impacted fitness:

If I want to go to check the mail now (I've got quite a hill to walk down and back) I wouldn't think of getting in the car to do it. The program's made me think differently. ... Now, because of the Fitbit, I know that I'm filling in part of what I should be doing during the day. Well, the first time I started to walk back I was puffing, I used to stop three times coming up the hill, and now I only have to stop once. (female, 76)

Seven participants noticed improvements in their fitness and strength, and a further six stated they had better balance and were more aware of fall-related risks. Two identified a reduction in anxiety and depression. Of the three participants who reported no impact, two had been very active before the program-"I was already there with my activity. ... I don't need any motivation, I'm doing it anyway" (female, 70) — and one of these had hoped to be allocated to the diet arm of the trial. The third was disappointed because she had expected the program to focus on "falling exercises" in which she would be taught how to right herself.

During the course of the interviews, several of those who had initially stated the program had had little or no impact identified (a) some increased walking, (b) a more rounded exercise repertoire, (c) greater fall-prevention awareness/skills, (d) weight loss, or (e) better informed and structured goals: "By joining the program I was able to already translate what I am doing now into more clearly defined goals" (female, 61).

It appeared that the duration of the program was important in providing time to trial strategies and developing habits that were sustained: "When I first started I only walked with my friend. Now I will walk on my own and I'm quite comfortable with doing that" (female, 76).

\section{Program Theory}

The constructs comprising our hybrid program theory were well represented in the data. The following results (Table 3) focus on how these constructs manifested in the CHAnGE trial.

\section{Potential Improvements}

The participants were asked for ideas that could strengthen CHAnGE, and nearly all made suggestions. We have reported on the four most salient of these.

Provide periodic group workshops. The most consistently suggested improvement to the intervention was encouraging a greater connection within the CHAnGE recruitment groups. The dominant idea was to supplement the current model with three "coach-led gatherings"/workshops for each group, one early in intervention, one midway, and one toward the end. This would provide opportunities for sharing ideas and experiences and for practicing exercises/techniques with hands-on guidance from the coach. A fun networking component could create stronger group connections and possibly encourage formal connections between those with similar goals and capabilities.

More face-to-face contact with coaches. Seven people asked for more face-to-face contact with their coach. The main suggestion was to add an additional home visit at the midway point: "It would certainly be nicer for me if there was an extra visit from X." Coaches could use this to review performance of exercises/techniques and provide an update on fall prevention in the home. It was thought that this would strengthen coach-participant relationships and possibly provide extra incentive to exercise.

Measure balance and provide feedback. Some participants who used CHAnGE to focus on fall prevention felt they would be more motivated with feedback that objectively measured balance and strength progress:

The Fitbit can tell you how many steps you've done and how many stairs you've climbed and how many calories you've lost and all those things, but it doesn't actually give you any information at all about whether your balance is improving. ... The only measure of how you're going in balance ... is entirely subjective. ... I think if it was possible to do some sort of test or measurement of how your balance was improving, that would really focus somebody like myself. (male, 69)

Offer dietary goal setting and advice. Several participants wanted to eat more healthily and lose weight. They argued that the other arm of the trial (which focused on diet) should be integrated with the PA/falls intervention to create a more holistic intervention: "I think with any exercise program there should be a member looking at the dietary and nutrition aspect. ... I think that's a part that was missing." However, this might not appeal to all potential participants. For example, one participant explained that he delayed signing up for CHAnGE because he thought the PA and falls arm of the trial were combined with the diet arm, and he did not want to account for his eating and drinking habits.

\section{Discussion}

Several potential essential ingredients (Dombrowski, O'Carroll, \& Williams, 2016; Haynes et al., 2016) of the CHAnGE trial were identified. 


\section{Table 3 An Overview of How Constructs in Our Program Theory Manifested in the CHAnGE Trial}

\begin{tabular}{|c|c|}
\hline Construct & How the construct manifested \\
\hline $\begin{array}{l}\text { Capability/ } \\
\text { competence }\end{array}$ & $\begin{array}{l}\text { This was most frequently talked about in terms of physical abilities, with an emphasis on } \\
\text { the impacts of aging (increased fatigue, arthritis, sore knees, and frailty), illness, and } \\
\text { injuries. Many of those with comparatively good health said they were "lucky" and felt an } \\
\text { obligation to look after what God or genetics had given them. Most participants did not } \\
\text { reflect on psychological capabilities, yet gave frequent examples of their insights and } \\
\text { initiatives. A small minority mentioned mental health frailties (anxiety, depression, } \\
\text { bipolar disorder), which they felt benefitted from PA but, paradoxically, also made it } \\
\text { harder to do. Many said that participation in CHAnGE had increased some capabilities. }\end{array}$ \\
\hline
\end{tabular}

Opportunity Opportunity was mentioned primarily in relation to local facilities and environment. Retirement villages and well-resourced sports, community, and aquatic centers provided valued (and often very social) activities that $1 / 3$ of participants tapped into. A few felt encouraged to walk because they lived in areas of natural beauty. Grandchildren and animals (dogs and poultry) were seen as positives because of the physicality that caring for them demanded. Some participants had poor local facilities and challenging circumstances. Caring and work commitments were common constraints, as hot or wet weather prevented over $1 / 3$ of participants from exercising at times.

Motivation Motivation was a conscious concept for all participants. Within the CHAnGE intervention, motivators for PA and fall prevention were identified as achievable goals backed by external accountability, supportive encouragement, noticeable improvements, and, in many cases, social interaction (including fun) and friendly competition. The desire to counter physical (and mental) decline and maintain independence and lifestyle quality were underlying drivers. For some, an injury or fall created a catalyst for action and an incentive for maintenance. Although many participants were highly motivated, a minority regarded motivation as elusive and were concerned they would be unable to maintain it long term. Thus, getting and staying motived was a goal in itself. Key threats were seen as the end of coaching (loss of their main source of accountability and encouragement), family demands, injury, and fatigue.

Autonomy Autonomy was primarily described in relation to independent living and seldom identified explicitly as part of the intervention experience, yet 22 participants alluded to it positively in their accounts of CHAnGE and why it worked for them. This suggests that program flexibility was viewed as crucial, but also taken for granted. There was a strong emphasis on negotiated goal-setting and self-direction, and over half the participants gave accounts of their own initiatives. It was not always clear where ideas had come from (the participant, their coach, another source, or a mix?), but participants were "owning" their goals and activities, and problem-solving creatively. Many suggested that selfdirected goals and activities supported longer term maintenance.

Relatedness This was a strong theme in the data as a force for both engagement and motivation. In addition to the many accounts of relatedness regarding coaches and fellow participants outlined earlier, nearly half the participants had supportive family and friends who had an "energising" effect on their motivation. Some younger family members provided company on walks and tech support with activity trackers. Many participants $(n=15)$ enjoyed social contact as part of their PA, but mostly in contexts that preceded CHAnGE. Those who were socially engaged in their PA expressed less concern about lack of motivation in the future, suggesting that companionship and fun may be important mechanisms in maintenance.

Competing Three quarters of participants described actual or potential tensions in prioritizing PA, demands with caring responsibilities and work pressures as key challenges. But those who were highly motivated found ways to prioritize activity: one participant took walks and attended gymnasium classes at 5.30 a.m. so she could care for her 100-year-old mother during the day.

\section{Illustrative quotes}

"I have knees that are not doing too well, get a bit sore, and a couple of years ago I almost contemplated having a knee replacement ... but now I wouldn't dare do it. ... I'd much rather do the exercises that put strength in my musculature around my knees. That's something I've gotten from you guys." (male, 76)

"They have such a wonderful YMCA near where I live. ... There's pools, the gym, there's classes; Tai Chi, yoga, you name it $\ldots$ all for $\$ 35$ a fortnight $\ldots$ and I can do about fifteen different things if I want in that fortnight. ... There's about twenty of us. [and] after it's all finished, we have coffee." (female, 70)

"I've never had anything like that [fall] before and it frightened the living daylights out of me. ... It gave me an insight of what could happen if you couldn't do anything and I thought, 'God, that happened to me,' you know? So I've been keeping exercise up." (female, 74)

"With this program I can choose whether to do a walk in the morning or last thing at night, so there's that huge flexibility. ... And the balance exercises can be done at home when you're brushing your teeth or cutting up veggies. It's good to be able to get the work in without having to commit to a place to go to do it." (female, 63)

"Doing it with friends is good ... I also have a neighbour and we go walking together. He's not on the program but since I've been going out with him I tend to walk longer as we look at old houses and parks and things in the neighbourhood." (female, 64)

"You've got to make the time ... there's no other way. You've got to slot it into everything else." (female, 76)

Note $\mathrm{PA}=$ physical activity; $\mathrm{CHAnGE}=$ Coaching for Healthy Ageing .

\section{High-Quality Health Coaching was Key to Participants' Positive Experience}

Despite sampling for maximum variation in engagement with CHAnGE, all participants expressed very positive views about health coaching. Combined with the activity tracker data (itself a probable essential ingredient), the coach/participant relationships mediated accountability and seemed to function as both an engagement and maintenance mechanism. "Quality" health coaching in this context involved (a) technical expertise that included competencies in physiotherapy, gerontology, and coaching; (b) high-level interpersonal skills; (c) intervention flexibility enabling coaches to focus on participant-directed goals; and (d) time frames and engagement strategies (such as home visits) that enabled coaches to build meaningful relationships and help participants routinize exercise. Other studies support the dual emphasis on psychosocial skills and technical know-how (Morera-Balaguer et al., 2019). For example, exercise group leaders are perceived as effective by older people when they are both demonstrably qualified and develop personal bonds with participants 
(e.g., Estabrooks et al., 2004). Our findings also highlight the role of participant-directed goals. Together, these points strongly resonate with the concept of therapeutic alliance. Key factors in a sound therapeutic alliance are shared goal-setting and decision making, resulting in a tailored action plan that is congruent with the client's values and circumstances and the development of a trusting and authentic person-centered relationship that emphasizes respect and autonomy (Kinney et al., 2018; Morera-Balaguer et al., 2019; Physiopedia Contributors, 2019).

The implications for program scalability are considerable, indicating that cost-reducing strategies, such as using lay coaches or solely text-based messaging, would remove or diminish one of the intervention's essential ingredients. The trial outcomes are not currently available, so the impact of the intervention is not known, but the participant perceptions are that high-quality supportive coaching is crucial. We note that smaller program effects may still be beneficial if interventions can be delivered to larger populations.

\section{Intervention Flexibility and Respect for Autonomy Promoted Engagement and Self-Efficacy}

The concept of autonomy permeated the data, both as a goal in itself (independent living) and as an essential aspect of the intervention: the participants could engage with personally meaningful activities and outcomes. Consistent with other studies and with self-determination theory, partnership approaches in which participants are supported to identify relevant and desirable goals are more likely to increase motivation and maintenance than directive approaches. (Fortier, Duda, Guerin, \& Teixeira, 2012; Oliveira et al., 2018; Stephan, Boiché, \& Le Scanff, 2010)

Our findings suggest that accountability functioned well in most cases, specifically because the goals were personalized and the coaches were person-focused. Thus, accountability was experienced as self-directed. Autonomous motivation is required for real accountability; otherwise, people "game" the system (Ryan \& Deci, 2017). Of particular interest are the many examples of participants setting aspirational goals that coaches then helped them "rein in." It seems coaches were supporting participants to navigate the tricky intersection of autonomy, capability, and opportunity shown in our program theory.

\section{Intervention Duration and Structure Helped to Embed PA and Fall-Prevention Strategies}

The duration of the intervention gave the participants opportunities to trial, refine, and embed practices in their day-to-day lives. Others have also found that participants often need time to discover what PA and fall-prevention strategies work for them and to experience benefits. For example, older adults in Devereux-Fitzgerald et al.'s review (2016) initially doubted their PA capacity, but became more confident over time. Our data and exploratory findings by others (Nagy, McMahon, Tapsell, Deane, \& Arenson, 2018) support the intuitive conclusion that longer duration and frequency of contact between the coach and participant, together with home visits and a communication method that allows dynamic conversation, provide a platform for establishing strong relationships.

\section{Key Areas of Learning That Have Implications for Intervention Improvement}

Social connection and relatedness needs are too diverse to manage effectively. Our data indicate that the current model of recruiting from community groups in the hope that existing connections will bolster PA had some positive effect where social relationships were already strong and where PA or health discourse was part of the mix, but was insufficient to generate new exercise groups or "buddy" relationships. The results indicate that methods for encouraging PA-related social connectivity could significantly enhance the CHAnGE intervention for some participants, but would require new strategies, possibly including ongoing facilitation. Periodic group workshops with participants (as suggested by interviewees in this study) is one option for leveraging social connections, but this would not address the enormous diversity in participants' social preferences, physical capabilities, and personalities. Social connection clearly motivated PA in some cases (this is supported by other studies [Allender et al., 2006; DevereuxFitzgerald et al., 2016]), but appeared to have minimal or no effect in others. Indeed, some preferred solo exercise. Several participants who would have liked to exercise with a friend were unable to do so not because they lacked social relationships, but because of incompatibility in terms of PA goals, exercise preferences, and/ or physical ability.

\section{Intervention design could encompass broader health goals.}

Several participants expressed interest in the dietary arm of the trial, either in preference to the PA and fall-prevention arm or as an adjunct to it. An Australian survey found that the most frequently selected responses regarding motivation for PA were weight loss or maintenance (Hoare et al., 2017). Therefore, some might find participation in this intervention more worthwhile if it incorporated a diet/nutrition and weight-focused component. However, our finding that some participants may avoid diet-related interventions that threaten valued behaviors suggests a need to emphasize autonomy in relation to diet, as well as exercise.

There may be more scope to emphasize enjoyment and life satisfaction. Our findings indicate that the participants were motivated to engage in PA and fall prevention by a mix of perceived benefits. Their awareness of the functional deficits often associated with aging provides opportunities at recruitment and in coaching sessions to explore ideas for off-setting pathological aging with PA (Saunders, 2015), particularly if this builds on personal experiences and concerns (e.g., of seeing peers incapacitated by a fall). Adherence to fall-prevention programs is strengthened when older people are concerned about the impact of potential falls on social activities (Batra et al., 2013). Periodic (or before and after) strength and balance measurements could increase motivation for these participants. There may also be a greater scope in highlighting the shorter term benefits from PA, for example, by using physiological monitoring to demonstrate immediate health impacts (Taylor \& Pescatello, 2016).

However, while most participants were keen to improve or sustain their health and quality of life, they were more enthusiastic about the pleasures of PA and how it shaped their week. For example, activity tracking encouraged participants to push themselves harder, but for many, this was underpinned by their sense of achievement in reaching goals and by using data conversationally, and often playfully or competitively, in social interactions. This is an example of "documented pleasure" (Phoenix \& Orr, 2014, p. 97), whereby gathering and reviewing data about PA and sharing it with others extends the pleasures of activity and has the potential to boost motivation and self-efficacy.

Recent reviews have emphasized the role of pleasure and satisfaction in PA, arguing that "Physical activity can help in regaining feelings of purpose, of being needed in collective group 
activity, and by creating habitual routine and structure to the day" (Morgan et al., 2019, abstract) and that, ultimately, the "functional and psychosocial benefits [of exercise] seem to outweigh long-term health benefits for older adults in terms of value of physical activity" (Devereux-Fitzgerald et al., 2016, p. 22). Older people may be keener to take part in interventions targeting falls when positive self-identity and positive benefits are emphasized (Nyman, 2011; Yardley, Donovan-Hall, Francis, \& Todd, 2006). So, while personal health outcomes remain a central driver (Teixeira et al., 2012), pleasure, relatedness, and increased self-esteem and efficacy can be equally motivating for many. This suggests a need to focus on successful and pleasurable activity experiences (Kosma \& Cardinal, 2016) and to reframe interventions to emphasize ways that PA can contribute to enjoyment, life satisfaction, purpose, and role fulfillment in older age (Morgan et al., 2019). Person-centered approaches are best suited to facilitating this at the individual level.

\section{Future Program Theory Could Usefully Include the Additional Theoretical Concepts That Informed This Study}

The core concepts in the hybrid theory that informed this study (Figure 1) were well represented in the data. The participants' views accorded broadly with the conceptual relationships in the COM-B model (Michie et al., 2011); for example, they described how their capabilities and circumstances (opportunities) influenced their motivation and impacted their behavior (West \& Michie, 2020). However, when discussing "what worked (or not)" in the intervention, their emphasis on concepts from self-determination theory (Ryan \& Deci, 2017) — autonomy and, particularly, relatedness — suggests that these are key mechanisms in the CHAnGE intervention. Although selfdetermination theory was not included formally in the CHAnGE program theory, the intervention design strongly supports autonomy and relatedness (as well as competence/capability - a merged concept from both theoretical models-see Figure 1). Our findings also indicate that the intervention is also being implemented with theoretical fidelity (Haynes et al., 2016) to these conceptual underpinnings and that this has enhanced participants' engagement and motivation. Consequently, self-determination theory should be included in future program theory for this and other similar interventions.

The participants' accounts of conflicting demands (Franco, Tong, et al., 2015) reinforced our view that this concept is best understood as an interaction between multiple elements in the COM-B model: capability, opportunity, and motivation. We did not systematically explore with the participants how conflicting demands were managed in relation to these elements, but this is a potential area for future investigation, which could lead to a better integration of the concept in our model.

\section{Strengths and Limitations}

This study contributes to the literature by providing insights into the views and experiences of a range of participants in the CHAnGE trial and identifying the essential ingredients of the intervention and theoretical implications. Designing and implementing the most effective interventions requires an in-depth understanding of participants and their contexts. Qualitative methods play an important role in this effort (Dombrowski et al., 2016). They also provide access to information that might be overlooked using quantitative methods. For example, during the course of our interviews, most of those who initially reported no impact from participating in the trial went on to identify areas of beneficial change in their PA that will not be captured in the trial outcome measures.

The participants were purposively recruited, so the final sample was not statistically representative of the wider trial cohort. Only those still enrolled in the intervention at the halfway stage (6 months) were eligible, so we do not know how the individuals who chose not to participate or dropped out perceived the intervention. There is much to learn from these individuals, but they are notoriously difficult to access in evaluations. The participant characteristics reflected those of the wider trial, so they were predominantly Australian-born native English-speakers with a moderate to high socioeconomic status and relatively high physical capability. Given that individuals with culturally and linguistically diverse backgrounds, low socioeconomic status, and physical disabilities are less likely to engage in PA and are at an increased risk of morbidity and mortality (Mendoza-Vasconez et al., 2016), the evaluation could be expanded to consider the potentially different contexts, needs, and preferences of these groups.

\section{Conclusion}

Our findings emphasize the synergistic benefits of flexible program plans that allowed person-centered goal setting; self-monitoring of progress via free activity trackers; regular guidance and encouragement from experienced, socially skilled coaches; and the yearlong duration of the intervention, which gave the participants time to trial, refine, and embed PA and fall-prevention activities and to form trusting relationships with the coaches. The PA-related social connectivity was highly motivating for some participants, but the intervention did not support this well. The self-reported impacts included increased levels of exercise, embedded activities, and greater positivity about PA and its benefits. Likely essential ingredients in the CHAnGE trial are identified, together with theoretical implications and potential areas for improving this and similar interventions.

\section{Acknowledgments}

We acknowledge and thank the following people: the three health coaches-Catherine Kirkham, Betty Ramsey, and Shona Manningwho helped with recruitment and provided guidance and data about the CHAnGE trial; Courtney West, for helping with the trial data; and the 32 participants who kindly gave their time to take part in an interview (Tiedemann et al., 2016).

\section{References}

Age UK. (2011). Healthy ageing evidence review. London, UK: Author. Allender, S., Cowburn, G., \& Foster, C. (2006). Understanding participation in sport and physical activity among children and adults: A review of qualitative studies. Health Education Research, 21(6), 826835. PubMed ID: 16857780 doi:10.1093/her/cyl063

Batchelor, F., Haralambous, B., Lin, X., Joosten, M., Williams, S., Malta, S., ... Fearn, M. (2016). Healthy Ageing Literature Review. Final Report to the Department of Health and Human Services. Retrieved from https://www2.health.vic.gov.au/-/media/health/files/collections/policiesand-guidelines/a/active-and-healthy-ageing-local-govt-action-guide--pdf.pdf

Batra, A., Page, T., Melchior, M., Seff, L., Vieira, E.R., \& Palmer, R.C. (2013). Factors Associated with the completion of falls prevention 
program. Health Education Research, 28(6), 1067-1079. PubMed ID: 24122324 doi:10.1093/her/cyt099

Bauman, A., Merom, D., Bull, F.C., Buchner, D.M., \& Fiatarone Singh, M.A. (2016). Updating the evidence for physical activity: Summative reviews of the epidemiological evidence, prevalence, and interventions to promote "active aging". The Gerontologist, 56(Suppl. 2), S268-S280. PubMed ID: 26994266 doi:10.1093/geront/gnw031

Braun, V., \& Clarke, V. (2006). Using thematic analysis in psychology. Qualitative Research in Psychology, 3(2), 77-101. PubMed ID: 22142324 doi:10.1191/1478088706qp063oa

Brickwood, K.-J., Williams, A.D., Watson, G., \& O’Brien, J. (2020). Older adults' experiences of using a wearable activity tracker with health professional feedback over a 12-month randomised controlled trial. Digital Health, 6, 205520762092167. PubMed ID: 32426152 doi:10. 1177/2055207620921678

Burton, N.W., Khan, A., \& Brown, W.J. (2012). How, where and with whom? physical activity context preferences of three adult groups at risk of inactivity. British Journal of Sports Medicine, 46(16), 11251131. PubMed ID: 22267568 doi:10.1136/bjsports-2011-090554

Cadilhac, D.A., Cumming, T.B., Sheppard, L., Pearce, D.C., Carter, R., \& Magnus, A. (2011). The economic benefits of reducing physical inactivity: An Australian example. International Journal of Behavioral Nutrition and Physical Activity, 8(1), 99. PubMed ID: 21943093 doi:10.1186/1479-5868-8-99

Daskalopoulou, C., Stubbs, B., Kralj, C., Koukounari, A., Prince, M., \& Prina, A.M. (2017). Physical activity and healthy ageing: A systematic review and meta-analysis of longitudinal cohort studies. Ageing Research Reviews, 38, 6-17. PubMed ID: 28648951 doi:10.1016/j. arr.2017.06.003

Dejonghe, L.A.L., Becker, J., Froboese, I., \& Schaller, A. (2017). Longterm effectiveness of health coaching in rehabilitation and prevention: A systematic review. Patient Education and Counseling, 100(9), 1643-1653. PubMed ID: 28465111 doi:10.1016/j.pec.2017.04.012

Devereux-Fitzgerald, A., Powell, R., Dewhurst, A., \& French, D.P. (2016). The acceptability of physical activity interventions to older adults: A systematic review and meta-synthesis. Social Science \& Medicine, 158, 14-23. PubMed ID: 27104307 doi:10.1016/j.socscimed.2016.04.006

Dombrowski, S.U., O'Carroll, R.E., \& Williams, B. (2016). Form of delivery as a key 'active ingredient' in behaviour change interventions. British Journal of Health Psychology, 21(4), 733-740. PubMed ID: 27709824 doi:10.1111/bjhp.12203

Eakin, E.G., Lawler, S.P., Vandelanotte, C., \& Owen, N. (2007). Telephone interventions for physical activity and dietary behavior change: A systematic review. American Journal of Preventive Medicine, 32(5), 419-434. PubMed ID: 17478269 doi:10.1016/j.amepre. 2007.01.004

Elliott, R., \& Timulak, L. (2005). Descriptive and interpretive approaches to qualitative research. In J. Miles\& P. Gilbert (Eds.), A handbook of research methods for clinical and health psychology. Oxford, UK: Oxford University Press.

Estabrooks, P.A., Munroe, K.J., Fox, E.H., Gyurcsik, N.C., Hill, J.L., Lyon, R., ... Shannon, V.R. (2004). Leadership in physical activity groups for older adults: A qualitative analysis. Journal of Aging and Physical Activity, 12(3), 232-245. PubMed ID: 15263101 doi:10. 1123/japa.12.3.232

Fortier, M.S., Duda, J.L., Guerin, E., \& Teixeira, P.J. (2012). Promoting physical activity: development and testing of self-determination theory-based interventions. International Journal of Behavioral Nutrition and Physical Activity, 9(1), 20. PubMed ID: 22385751 doi:10.1186/1479-5868-9-20

Franco, M.R., Howard, K., Sherrington, C., Ferreira, P.H., Rose, J., Gomes, J.L., \& Ferreira, M.L. (2015). Eliciting older people's preferences for exercise programs: A best-worst scaling choice experiment. Journal of Physiotherapy, 61(1), 34-41. PubMed ID: 25499647 doi:10.1016/j.jphys.2014.11.001

Franco, M.R., Tong, A., Howard, K., Sherrington, C., Ferreira, P.H., Pinto, R.Z., \& Ferreira, M.L. (2015). Older people's perspectives on participation in physical activity: A systematic review and thematic synthesis of qualitative literature. British Journal of Sports Medicine, 49(19), 1268-1276. PubMed ID: 25586911 doi:10.1136/bjsports2014-094015

Fusch, P.I., \& Ness, L.R. (2015). Are we there yet? Data saturation in qualitative research. The Qualitative Report, 20(9), 1408-1416.

Hamer, M., Lavoie, K.L., \& Bacon, S.L. (2014). Taking up physical activity in later life and healthy ageing: The English longitudinal study of ageing. British Journal of Sports Medicine, 48(3), 239-243. PubMed ID: 24276781 doi:10.1136/bjsports-2013-092993

Haynes, A., Brennan, S., Redman, S., Williamson, A., Gallego, G., \& Butow, P. (2016). Figuring out fidelity: A worked example of the methods used to identify, critique and revise the essential elements of a contextualised intervention in health policy agencies. Implementation Science, 11, 1-18. PubMed ID: 26912211 doi:10.1186/s13012016-0378-6

Heath, G.W., Parra, D.C., Sarmiento, O.L., Andersen, L.B., Owen, N., Goenka, S., ... Lancet Physical Activity Series Working Group. (2012). Evidence-based intervention in physical activity: Lessons from around the world. The Lancet, 380(9838), 272-281. PubMed ID: 22818939 doi:10.1016/S0140-6736(12)60816-2

Hill, A.-M. (2018). Promotion of physical activity for the general older population. In The Palgrave handbook of ageing and physical activity promotion (pp. 103-122). Cham, Switzerland: Springer.

Hill, R.L., \& Heesch, K.C. (2018). The problem of physical inactivity worldwide among older people. In S.R. Nyman, A. Barker, T. Haines, K. Horton, C. Musselwhite, G. Peeters, C.R. Victor, \& J.K. Wolff (Eds.), The Palgrave handbook of ageing and physical activity promotion (pp. 25-41). Cham, Switzerland: Springer International Publishing.

Hoare, E., Stavreski, B., Jennings, G.L., \& Kingwell, B.A. (2017). Exploring motivation and barriers to physical activity among active and inactive australian adults. Sports, 5(3), 47. PubMed ID: 29910407 doi:10.3390/sports5030047

Hornyak, V., Brach, J.S., Wert, D.M., Hile, E., Studenski, S., \& VanSwearingen, J.M. (2013). What is the relation between fear of falling and physical activity in older adults? Archives of Physical Medicine and Rehabilitation, 94(12), 2529-2534. doi:10.1016/j. apmr.2013.06.013

Johnson, R., \& Waterfield, J. (2004). Making words count: The value of qualitative research. Physiotherapy Research International, 9(3), 121-131. PubMed ID: 15560669 doi:10.1002/pri.312

Kang, M., Marshall, S.J., Barreira, T.V., \& Lee, J.-O. (2009). Effect of pedometer-based physical activity interventions: A meta-analysis. Research Quarterly for Exercise and Sport, 80(3), 648-655. PubMed ID: 19791652 doi:10.1080/02701367.2009.10599604

Kinney, M., Seider, J., Beaty, A.F., Coughlin, K., Dyal, M., \& Clewley, D. (2018). The impact of therapeutic alliance in physical therapy for chronic musculoskeletal pain: A systematic review of the literature. Physiotherapy Theory and Practice,36(8), 886-898. PubMed ID: 30265840 doi:10.1080/09593985.2018.1516015

Kosma, M., \& Cardinal, B.J. (2016). The transtheoretical model, physical activity, and falls risks among diverse older adults. Activities, Adaptation \& Aging, 40(1), 35-52. doi:10.1080/01924788.2016. 1127051

Koster, A., Stenholm, S., \& Schrack, J.A. (2018). The Benefits of physical activity for older people. In S.R. Nyman, A. Barker, T. Haines, K. Horton, C. Musselwhite, G. Peeters, C.R. Victor, \& J.K. Wolff (Eds.), 
The Palgrave handbook of ageing and physical activity promotion (pp. 43-60). Cham, Switerland: Palgrave Macmillan.

Liddy, C., Johnston, S., Irving, H., Nash, K., \& Ward, N. (2015). Improving awareness, accountability, and access through health coaching: Qualitative study of patients' perspectives. Canadian Family Physician, 61(3), e158-e164. PubMed ID: 2593248

Malterud, K., Siersma, V.D., \& Guassora, A.D. (2015). Sample size in qualitative interview studies: Guided by information power. Qualitative Health Research, 26(13):1753-1760. PubMed ID: 26613970 doi:10.1177/1049732315617444

Manzano, A. (2016). The craft of interviewing in realist evaluation. Evaluation, 22(3), 342-360. doi:10.1177/1356389016638615

McMurdo, M.E.T., Sugden, J., Argo, I., Boyle, P., Johnston, D.W., Sniehotta, F.F., \& Donnan, P.T. (2010). Do pedometers increase physical activity in sedentary older women? A randomized controlled trial. Journal of the American Geriatrics Society, 58(11), 2099-2106. PubMed ID: 21054290 doi:10.1111/j.1532-5415.2010.03127.x

Mendoza-Vasconez, A.S., Linke, S., Muñoz, M., Pekmezi, D., Ainsworth, C., Cano, M., ... Larsen, B.A. (2016). Promoting physical activity among underserved populations. Current Sports Medicine Reports, 15(4), 290297. PubMed ID: 27399827 doi:10.1249/JSR.0000000000000276

Mercer, K., Li, M., Giangregorio, L., Burns, C., \& Grindrod, K. (2016). Behavior change techniques present in wearable activity trackers: A critical analysis. JMIR mHealth uHealth, 4(2), e40. PubMed ID: 2712245 doi: $10.2196 /$ mhealth.4461

Michie, S., van Stralen, M.M., \& West, R. (2011). The behaviour change wheel: A new method for characterising and designing behaviour change interventions. Implementation Science, 6(1), 42. PubMed ID: 21513547 doi:10.1186/1748-5908-6-42

Morera-Balaguer, J., Botella-Rico, J.M., Catalán-Matamoros, D., Martínez-Segura, O.-R., Leal-Clavel, M., \& Rodríguez-Nogueira, Ó. (2019). Patients' experience regarding therapeutic person-centered relationships in physiotherapy services: A qualitative study. Physiotherapy Theory and Practice. Advance online publication. PubMed ID: 31002005 doi:10.1080/09593985.2019.1603258

Morgan, G.S., Willmott, M., Ben-Shlomo, Y., Haase, A.M., \& Campbell, R.M. (2019). A life fulfilled: Positively influencing physical activity in older adults-A systematic review and meta-ethnography. BMC Public Health, 19(1), 362-362. PubMed ID: 30940111 doi:10.1186/ s12889-019-6624-5

Nagy, A., McMahon, A., Tapsell, L., Deane, F., \& Arenson, D. (2018). Therapeutic alliance in dietetic practice for weight loss: insights from health coaching. Nutrition \& Dietetics, 75(3), 250-255. PubMed ID: 29436162 doi:10.1111/1747-0080.12405

Nyman, S.R. (2011). Psychosocial issues in engaging older people with physical activity interventions for the prevention of falls. Canadian Journal on Aging/La Revue canadienne du vieillissement, 30(1), 4555. PubMed ID: 21356153 doi:10.1017/S0714980810000759

Oliveira, J.S., Hassett, L., Sherrington, C., Ramsay, E., Kirkham, C., Manning, S., \& Tiedemann, A. (2018). Factors associated with the setting of health-related goals among community-dwelling older people. Journal of Aging and Physical Activity, 26(3), 499-505. PubMed ID: 29091515 doi:10.1123/japa.2017-0172

Oliveira, J.S., Sherrington, C., Amorim, A.B., Dario, A.B., \& Tiedemann, A. (2017). What is the effect of health coaching on physical activity participation in people aged 60 years and over? A systematic review of randomised controlled trials. British Journal of Sports Medicine, 51(19), 1425-1432. PubMed ID: 28320732 doi:10.1136/bjsports2016-096943

Oliveira, J.S., Sherrington, C., Paul, S.S., Ramsay, E., Chamberlain, K., Kirkham, C., ... Tiedemann, A. (2019). A combined physical activity and fall prevention intervention improved mobility-related goal attainment but not physical activity in older adults: A randomised trial. Journal of Physiotherapy, 65(1), 16-22. doi:10.1016/j. jphys.2018.11.005

Oliveira, J.S., Sherrington, C., Zheng, E.R., Franco, M.R., \& Tiedemann, A. (2019). Effect of interventions using physical activity trackers on physical activity in people aged 60 years and over: A systematic review and meta-analysis. British Journal of Sports Medicine. Advance online publication. PubMed ID: 31399430 doi:10.1136/ bjsports-2018-100324

Patton, M.Q. (1999). Enhancing the quality and credibility of qualitative analysis. Health Services Research, 34(5), 1189-1208. PubMed ID: 10591279

Paul, S.S., Tiedemann, A., Hassett, L.M., Ramsay, E., Kirkham, C., Chagpar, S., \& Sherrington, C. (2015). Validity of the fitbit activity tracker for measuring steps in community-Dwelling older adults. BMJ Open Sport \& Exercise Medicine, 1(1), e000013. PubMed ID: 27900119 doi:10.1136/bmjsem-2015-000013

Phoenix, C., \& Orr, N. (2014). Pleasure: A forgotten dimension of physical activity in older age. Social Science \& Medicine, 115, 94-102. PubMed ID: 24955874 doi:10.1016/j.socscimed.2014.06.013

Physiopedia Contributors. (2019, April 17). Therapeutic alliance. Retrieved from www.physio-pedia.com/index.php?title=Therapeutic_ Alliance\&oldid $=209034$

Rethorn, Z.D., \& Pettitt, C.D. (2019). What is the effect of health coaching delivered by physical therapists? A systematic review of randomized controlled trials. Physical Therapy, 99(10), 1354-1370. doi:10.1093/ ptj/pzz098

Rhodes, R.E., \& Pfaeffli, L.A. (2010). Mediators of physical activity behaviour change among adult non-clinical populations: A review update. International Journal of Behavioral Nutrition and Physical Activity, 7(1), 37. doi:10.1186/1479-5868-7-37

Ryan, E., \& Deci, R. (2017). Self-determination theory: Basic psychological needs in motivation, development, and wellness. New York, NY: Guilford Publishing.

Saunders, T. (2015, June 2). Many health impacts of aging are due to inactivity-Not getting old. MedicalXpress.

Stathi, A., Fox, K.R., \& McKenna, J. (2002). Physical activity and dimensions of subjective well-being in older adults. Journal of Aging and Physical Activity, 10(1), 76-92. doi:10.1123/japa.10.1.76

Stathi, A., Fox, K.R., Withall, J., Bentley, G., \& Thompson, J.L. (2014). Promoting physical activity in older adults: A guide for local decision makers. Avon network for the promotion of active ageing in the community.

Stathi, A., McKenna, J., \& Fox, K.R. (2010). Processes associated with participation and adherence to a 12-month exercise programme for adults aged 70 and older. Journal of Health Psychology, 15(6), 838847. doi:10.1177/1359105309357090

Stephan, Y., Boiché, J., \& Le Scanff, C. (2010). Motivation and physical activity behaviors among older women: A self-determination perspective. Psychology of Women Quarterly, 34(3), 339-348. doi:10. 1111/j.1471-6402.2010.01579.x

Taylor, B.A., \& Pescatello, L.S. (2016). For the love of it: Affective experiences that may increase physical activity participation among older adults. Social Science \& Medicine, 161, 61-63. PubMed ID: 27258016 doi:10.1016/j.socscimed.2016.05.034

Teixeira, P.J., Carraça, E.V., Markland, D., Silva, M.N., \& Ryan, R.M. (2012). Exercise, Physical activity, and self-determination theory: A systematic review. International Journal of Behavioral Nutrition and Physical Activity, 9(1), 78-78. PubMed ID: 22726453 doi:10.1186/ 1479-5868-9-78

Thompson, W.G., Kuhle, C.L., Koepp, G.A., McCrady-Spitzer, S.K., \& Levine, J.A. (2014). "Go4life" exercise counseling, accelerometer 
feedback, and activity levels in older people. Archives of Gerontology and Geriatrics, 58(3), 314-319. PubMed ID: 24485546 doi:10.1016/ j.archger.2014.01.004

Thorne, S. (2000). Data analysis in qualitative research. Evidence Based Nursing, 3(3), 68-70. doi:10.1136/ebn.3.3.68

Thorne, S. (2008). Interpretive description (Vol. 2). Walnut Creek, CA: Left Coast Press.

Tiedemann, A., Hassett, L., \& Sherrington, C. (2015). A novel approach to the issue of physical inactivity in older age. Preventive Medicine Reports, 2, 595-597. doi:10.1016/j.pmedr.2015.07.008

Tiedemann, A., Rissel, C., Howard, K., Tong, A., Merom, D., Smith, S., . . . Sherrington, C. (2016). Health coaching and pedometers to enhance physical activity and prevent falls in community-dwelling people aged 60 years and over: Study protocol for the Coaching for Healthy AGEing (CHAnGE) cluster randomised controlled trial. BMJ Open, 6(5), e012277. doi:10.1136/bmjopen-2016-012277

Tong, A., Sainsbury, P., \& Craig, J. (2007). Consolidated criteria for reporting qualitative research (Coreq): A 32-item checklist for interviews and focus groups. International journal for quality in health care, 19(6), 349-357. PubMed ID: 17872937 doi:10.1093/intqhe/ mzm042

West, R., \& Michie, S. (2020). A brief introduction to the Com-B model of behaviour and the prime theory of motivation [V1]. Qeios, WW04E6.

White, D.E., Oelke, N.D., \& Friesen, S. (2012). Management of a large qualitative data set: establishing trustworthiness of the data. International Journal of Qualitative Methods, 11(3), 244-258. doi:10.1177/160940691201100305

Wolever, R.Q., Simmons, L.A., Sforzo, G.A., Dill, D., Kaye, M., Bechard, E.M., ... Yang, N. (2013). A systematic review of the literature on health and wellness coaching: Defining a key behavioral intervention in healthcare. Global Advances in Health and Medicine, 2(4), 38-57. PubMed ID: 24416684 doi:10.7453/gahmj.2013.042

World Health Organization. (2015). World report on ageing and health. Geneva, Switzerland: Author.

Yardley, L., Donovan-Hall, M., Francis, K., \& Todd, C. (2006). Older people's views of advice about falls prevention: A qualitative study. Health Education Research, 21(4), 508-517. PubMed ID: 16467173 doi:10.1093/her/cyh077 